\title{
Developing a smartphone app for m-government in agriculture
}

\author{
Sotiris Karetsos ${ }^{1}$, Constantina Costopoulou ${ }^{2}$, Alexander Sideridis ${ }^{3}$
}

\section{N F O}

Received 20 Mar. 2014

Accepted 5 May. 2014

Available on-line 10 Jul. 2014

Responsible Editor: K. Rajkai

\section{Keywords:}

mobile phones, mobile devices, e-government, m-government, agriculture, farmers

\begin{abstract}
$\underline{\text { A B S T R A C T }}$
The high penetration of smartphones and the advanced capabilities of the software that they can host, forces public agencies to rapidly transform their services in the mobile government environment for maximizing utility of services and minimizing costs. In this context, the aim of the paper is primarily to review the smartphone use and capabilities in agriculture. An overview of apps targeted to the agricultural business sector is provided. Secondly, the potential use of smartphones for mobile government is discussed and a transactional mobile government app for the Android operating system is proposed based on a case study for agriculture. The mobile government app is based on a previously developed electronic government system for farmers. Design and technical aspects for the implementation of the proposed app are presented and discussed. Such apps hope to be a promising solution for farmers enabling them to access government information and transact with public agencies at their convenience and at a location of their choice.
\end{abstract}

\section{Introduction}

Mobile communication technology forced governments to be transformed from electronic government (e-government) to mobile government (m-government). It provides citizens and businesses with an immediate access to certain government information and services, on anywhere and anytime basis. While e-government is the practice of information and communication technologies (ICT) to improve the efficiency of the governmental services which are provided to citizens, employees, businesses and agencies (Carter and Belanger, 2005), m-government refers to the practice of mobile and wireless communication technologies in government administration and its delivery of information and services to citizens and businesses. Usually, m-government is considered as a subset of e-government comprising an alternative provisioning channel (Ntaliani et al., 2008).

The development of e-government services has been traditionally based on non-mobile services but now, with the high penetration rate of mobile devices in the population, more people are able to use $\mathrm{m}$ government services. The International Telecommunication Union (ITU) estimated 6.8 billion mobile subscriptions worldwide in 2013 (ITU, 2014). Moving from customary, traditional paper-based services, or even wire Internet access based services to the wireless Internet services, m-government provides the ability to citizens and businesses to be supplied with the most suitable and quickest means of acquiring government services. Therefore, through mobile devices, governments can reach a greater number of citizens improving communication effectiveness and maintaining relationships (Hung and Lin, 2013). Additionally, the digital divide is gradually decreased with significant benefits for both citizens and governments.

The generic term "mobile device" is related to a mixture of devices that permit the people to access data and information from anywhere. ICT has allowed mobile devices to do nearly anything which had previously been done with personal computers. Mobile devices include cell phones, portable devices

\author{
1 Sotiris Karetsos \\ Department of Agricultural Economics and Rural Development, Agricultural University of Athens \\ karetsos@aua.gr \\ 2 Constantina Costopoulou \\ Department of Agricultural Economics and Rural Development, Agricultural University of Athens \\ tina@aua.gr \\ 3 Alexander Sideridis \\ Department of Agricultural Economics and Rural Development, Agricultural University of Athens \\ as@aua.gr
}

ISSN 2061-862X (http://www.magisz.org/journal)

Sotiris Karetsos, Constantina Costopoulou, Alexander Sideridis: Developing a smartphone app for m-government in agriculture 
such as personal digital assistant (PDA) and lately smartphones. In particular, a smartphone combines the utility of a cell phone and a PDA into one device. Smartphones are now equipped with highresolution touch screen display, innovative sensors, camera, more memory and processing capabilities as well as effective mechanisms for saving power. They have Web browsing capabilities, Wi-Fi connectivity and the ability to accept sophisticated applications and access the Internet over a $3 \mathrm{G}$ or 4G/LTE wireless network. The most well-known mobile operating systems (OS) for smartphones are Android, Symbian, iOS, BlackBerry OS and WindowsPhone.

The intrusion of smartphones is enhancing day by day. The advance of smartphones that can be used virtually anywhere, gives users access to all information of the Internet and puts tools such as calculators and record keeping literally in the palm of one's hand. On the other hand there are thousands of mobile applications (apps) related to Android, iOS and the other platforms that offer several advantages and functionalities. However the development of mobile apps and in particular smartphone apps is currently focused on private consumption. It is known several efforts of penetration of mobile technology within the government for almost a decade now, but the mobile features are not widely utilized in e-government services (Chang and Kuo, 2013; Wimmer et al., 2013).

While mobile devices are increasingly being used in daily activities (e.g. learning, tourism, medicine) there is a need for research on mobile devices used in interactive and transactional egovernment services. In spite of the necessity of research on m-government apps, as a new channel of delivering government services although, there is a restricted number of studies dealing with it (Eom et al., 2012). It merits noting that in this paper the term m-government apps or public apps is used to depict smartphone applications provided by public agencies to achieve more accessible, efficient and effective government.

In this light, this paper presents the design of transactional m-government apps for agriculture based on the Android platform. The business sector of agriculture has been selected because farmers are a special group of users. They have a distance from decision and policy-making centres; it is often neither feasible (due to lack of transportation, time, money, or bad climate conditions) nor suitable to travel for gaining the necessary information or for using the available public services in their disposition (Chatzinotas et al., 2006; Ntaliani et al., 2008). On the other hand, smartphones have penetrated in almost all the environments where people carry out their everyday activities, and perform tasks that are normally run in personal computers. Also, mobile literacy is higher than computer literacy, even though mobile devices might have inconvenient user interfaces. Therefore, $\mathrm{m}$ government apps appear to be a promising solution for farmers, agriculturalists and extension staff.

The structure of the paper is as follows: Section 2 provides an overview of smartphone apps in agriculture. Section 3 presents an e-government system for agriculture called Agroportal which has been previously described by the authors (Ntaliani et al., 2006). Four agricultural fields (i.e. apiculture, sericulture, forestry and horticulture) were put under study and related apps are disused. Also, it presents the design of a transactional m-government app for agriculture. Finally, section 4 concludes the work and provides directions for future work.

\section{Background}

\subsection{Use of mobile devices in agriculture}

Agricultural sector is among the most important business sectors in the world since it is the main food supplier. However, agricultural sector is one of the business sectors that have been left aside in terms of the application of new technologies. According to a study conducted by (Jain et al., 2014), "agricultural information system needs to be developed based on the mass communication technology such as mobile systems. It is also noted that localization and native language of farmers are the concerns to be incorporated into the systems". The aforementioned study suggests also that farmers "need specialized information for their crops and cultivation techniques but it is not always easy to find it. More specifically, agricultural practices need precise and accurate information to be disseminated promptly to farmers so that better decisions such as managing farm fields, making continuous and scientific changes in their production systems and grabbing advantage of market 
opportunities can be made (Jain et al., 2014). Extending the aforementioned approach we can include also the provision of governmental services as a means to better administer their interaction with governmental agencies.

Stakeholders involved in the agricultural sector are progressively using ICT technology and sometimes with remarkable proportions. In the reality, a research conducted in 2011 in USA demonstrated that farmers are rapidly adopting smartphone technology and, in fact, are making greater use of the devices than does the general public. The research results showed that farmers are utilizing smartphones more as a working tool and less for entertainment (Agriculture.com, 2011; USA, 2013). There had been a recent survey in Canada by Farm Credit which showed that nearly 30\% of farmers have smartphones. This occurs in other well developed countries too. Farmers are conducting a range of work-related tasks with the devices including sending/receiving email; checking weather, news, and markets; and text messaging. More than $70 \%$ of survey respondents say they access agriculture information and services on their phones. Farmers increasingly prefer to get to the Internet with their mobile phones vs. other devices. About a third of survey respondents say they utilize their mobile phones to access the Internet as much as they do with other devices, such as desktop computers. The same number says they use their phones to access the Internet daily. Younger farmers are having greater use of smartphones: $71 \%$ of respondents under age 39 say they own a smartphone, in comparison with the overall total of 39\% (Agriculture.com, 2011; Chang and Kuo, 2013; Educase.com, 2013; Digby.com, 2013).

\subsection{Smartphone Apps for agriculture}

There are many agriculture smartphone apps on crop prices, weather conditions, inventory levels and innovative farming techniques and machinery. For example in Australia some samples include tracking and managing livestock, monitoring calving, managing water points, managing irrigation, talking between machinery, remote performing of roles such as unloading grain, monitoring sensors in crops, marketing produce, estimating and mapping yield, performing as substitute tools (such as spirit levels), calculating area, mapping soil types etc. However apps specifically for agriculture are still limited. Up to now, the most dominant app is the apps related to weather (Roberts and McIntosh, 2012). Other apps related to record keeping and accessing agricultural news and technical information (Lorimer, 2012).

Digital technology and agricultural expertise and knowledge have been merged, thus an assortment of smartphone apps according to the needs of farmers has been evolved. These apps can be grouped into the following main categories, namely agriculture management information apps; agriculture information resource apps; agriculture calculator apps; agriculture news apps, weather apps and mgovernment apps. In the following some examples are given mainly from USA and Australia.

Agriculture Management Information Apps: Applications that are included in this category are in a great deal mobile extension of an operational management system or a farm. For instance farmers can decide what varieties and other inputs want before planting starts (e.g. Virtual Farm Manager App). They can generate electronic maps of fields to keep a history of growing crops in the fields (fertilizing, planting, harvesting), to take notes on the fields as points of interest (e.g. warehouses, gas stations), to keep the location of objects in the farm (e.g. soil sampling for agrochemical laboratory), to keep a diary of field operations for each field (e.g. eFarmer App). Professionals in the green industry and homeowners can have access to pictures, information, and recommendations for managing weeds, diseases, and pests (e.g. Turfgrass Management App). Ranchers and grassland managers can keep records of grazing use and range and pasture conditions (e.g. South Dakota Rangeland and Pasture Grazing Records App). Farmers can access timely, accurate data for each and every one of the climate/moisture monitoring stations or irrigation sets in their fields (e.g. PureSense Irrigation Manager App).

Agriculture Information Resource Apps: This category includes apps that are first and foremost utilized as a lookup implements or else a tool which assists to the identification of 
species, reviews regulations and takes expertise on a subject. For example farmers, agricultural students and any other interested in agriculture can get information in several categories such as farmer information, general information, fertilizers and pesticides prices etc. (e.g. Agriculture Information). Farmers can have access to a vocabulary of 4,500 words and terms utilized for the field of entomology (e.g. Entomology Dictionary). Farmers can have access to crop disease resistance ratings. They can compare the resistance ratings of a number of crop varieties for different crop diseases (e.g. Crop Disease). Also, an innovative Greek mobile app is an app, named ToTheShelf that links growers to traders and vice versa locally or globally. Agricultural products can have access to the local or global market fast and easy and go from the field to the shelf. Up till there are about 500 subscribers.

Agriculture Calculator Apps: This group of apps includes smartphone tools to help make in field calculations without having to head back to the home office. For instance farmers can based on where the grain markets are currently trading (e.g. Farmer's Partner). Also, farmers can measure the maturity of a crop by viewing current and past growing degree days data of farm's location (e.g. Growing Degree Days). Farmers have the ability to obtain local, personalized information that is crucial for their farming operation (e.g. Growers Edge). Farmers can search for used farm equipment via categories or a selection of other criteria such as price, year (e.g. Landwirt Used Farm Machinery Search).

Agriculture News Apps: These are a token of agri-media focused news aggregators. For instance farmers can have access to a website presenting agricultural management news, markets, weather, several alerts, farm business blogs, articles and radio (e.g. AGWeb). Farmers can reach local agricultural news, grain and livestock markets, weather and blogs (e.g. Farm Progress). Farmers have the ability to customize lists of markets as well as to find market commentary, news and audio (e.g. Farm Futures). Farmers can receive local market commentary and agricultural news and compare risk management options (e.g. Growers Edge). Greek farmers can be informed using the AgroNews.gr app which provides access to the latest agricultural news.

Weather Apps: This category describes only a sample of smartphone weather applications, since there are lots of them. Some apps are quite focused on farmers' needs to whom they offer the ability to access weather pinpointed on their fields and find their local and best price bids within a 100-miles of their location (e.g. Growers Edge). In Australia, there are about seven weather apps (Weatherzone Plus, Elders Weather, Yr.No., Rain, Pocket Weather AU, $\mathrm{Oz}$ Weather, Aus Weather) and each one of them provides different advantages and user's preferences. In Greece, there are few weather apps for general use such as Meteo and MeteoKairos.

M-government Apps: In this category are included some information apps provided by governmental agencies. For example in Australia farmers can pick up varieties of barley, canola, chickpeas, faba beans, field peas, lupins, oats, triticale and wheat (e.g. CropMate Variety Chooser). Farmers can identify the most ordinary weeds in southern Australia (e.g. Weeds: the Ute Guide). In addition they can compare current crop disease resistance ratings, disease symptoms, map diseases and share images of diseases with others (Crop Diseases). They can use GPS to know heritage places, wetlands, protected species, protected areas, weeds and invasive species around their fields (MyEnvironment).

\section{The Agroportal system extended as a smartphone app}

\subsection{The notion of the Agroportal system}

Agroportal system is an e-government portal which aims at supporting agribusinesses (i.e. a farmer is also considered as an agribusiness) in transacting with Greek agricultural 
governmental agencies. It is based on the notion of one-stop shop that refers to the integration of information and services to a single point of access from the user's point of view. An agribusiness can access the Agroportal system through a PC with connection to the Internet in order to reach information and governmental services, as well as send and receive Short Message Service (SMS) messages to a mobile phone in order to request information or apply for a public service (Chatzinotas et al., 2006; Ntaliani et al., 2006). The design and development of the Agroportal system based on methodology described in previous works. The main aspect of that research (i.e. 435 questionnaires) is the preference of farmers to use their mobile phones for e-government services. Therefore, the current work is an extension of the previous analysis to include the new capabilities of mobile phones. Agroportal provides the following types of services:

- Information Services: These services aim at providing the users with relevant information about the portal's domain of interest. There are three main information sections: news, frequently asked questions (FAQs) and useful links.

- Governmental Services: These services are divided into e-government and m-government services. The e-government services enable (a) the electronic submission of applications by the users; (b) the processing of the application by the appropriate government actor; and (c) the forwarding of the application response back to the user. The m-government services provide information via SMS messages for: agricultural products and their cultivation; epidemic alerts for the outbreak of an epidemic and proposing measures for confrontation; weather alerts for extreme conditions; legislation news for the issuing or abolition of related law; administrative information for deadlines (e.g. submission of applications); market information for traders, wholesalers, processors (e.g. price tendencies, demand forecasting and trends); chat among agribusinesses.

- Value-added Services: The communication services are meant to enable the communication between the users and the government actors. The portal aims at providing synchronous communication methods (e.g. real-time chat), as well as asynchronous communication methods (e.g. email, forum, private messages).

The extended notion of the Agroportal is presented in the following figure 1. Therefore, the system can be accessed through the Web at the following URL: http://meli.aua.gr/agroportal/. Also the agribusinesses are able to exchange informative SMS regarding several agricultural issues as described above. The extended version of the system provides availability also on smartphones and tablets.

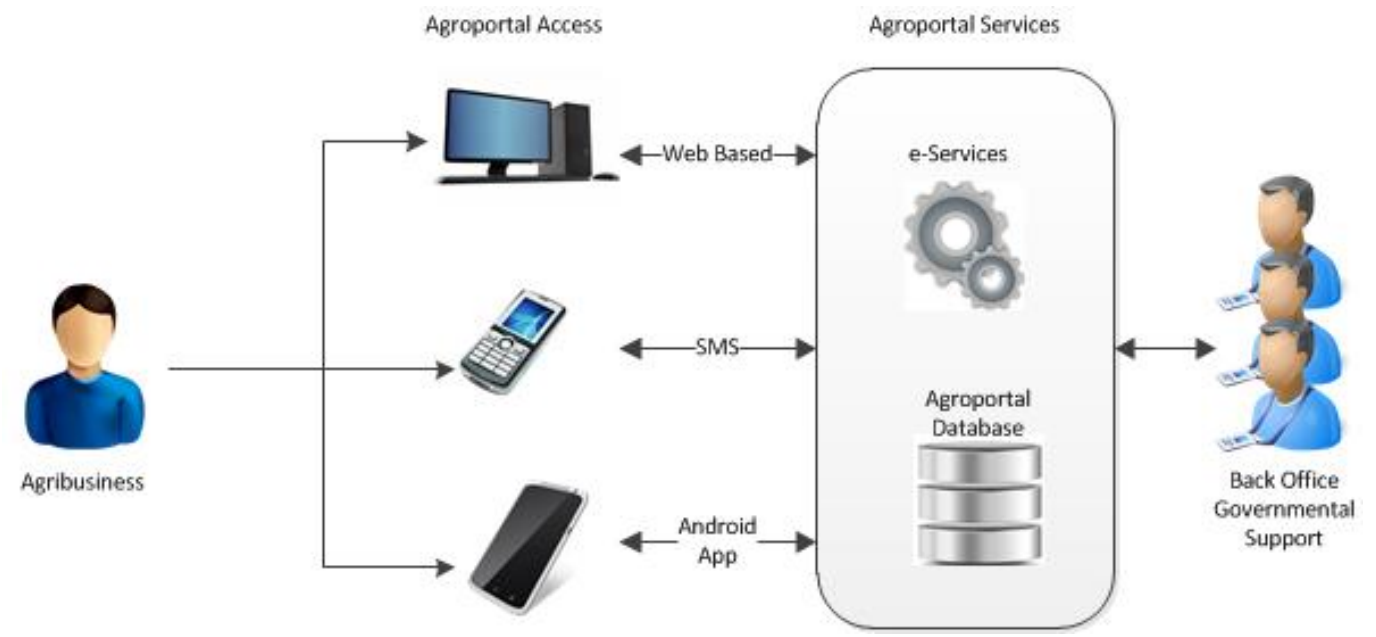

Figure 1. The extended notion of Agroportal system 


\subsection{The smart agricultural services}

The proposed app has been developed for the Android platform for smartphones. This decision is based on the rationale that the Android OS has greater freedom in its development program. Android is an open source mobile operating system developed by Google for mobile devices that uses a modified Linux kernel. Moreover, an app is a software application running on such a platform. The app developed using the Android Developer Tools (ADT) v22.2.1, and tested for displays from 3.2 up to 10.1 inches. The minimum required Android version is 2.2 (Froyo) and the target Android version is 4.3 (Jelly Bean).

Much of the development effort has involved also configuring Agroportal Web services which are the core of the app's functionality. The key functionality of the developed app, at present, includes a front screen comprising a list of eight options namely horticulture, apiculture, sericulture, forestry, agricultural news, FAQ, forums, and weather (figure 2). Touching on the options horticulture, apiculture, sericulture or forestry another list of options is revealed. Figure 3 presents the menu for horticulture. Figures 4 and 5 present informative content for forestry and apiculture respectively. Figure 6 presents an m-government service for apiculture and specifically the application for issuing apiculture booklet. The application for ordering silkworm eggs, an m-government service for sericulture, is presented in figure 7 .

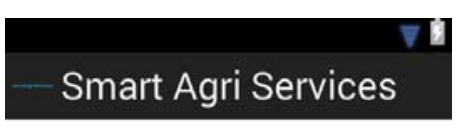

\begin{tabular}{|c|}
\hline ^AXANOKOMIA \\
\hline 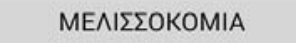 \\
\hline ЕНРОТРОФІА \\
\hline$\triangle A \Sigma O \Pi O N I A$ \\
\hline АГРОTIKA NEA \\
\hline PQTH \\
\hline 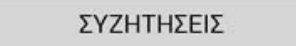 \\
\hline KAIPOS \\
\hline
\end{tabular}

Figure 2. The front screen
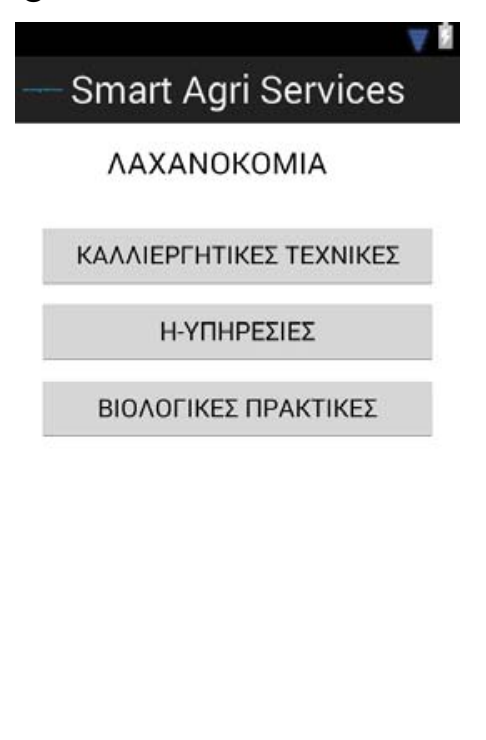

Figure 3. List of options for the horticulture case



Figure 4. Informative content for forestry 


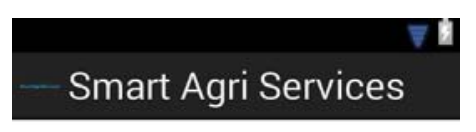

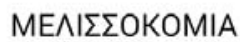

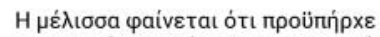

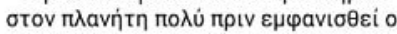

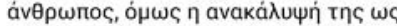

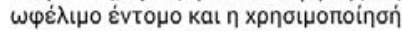

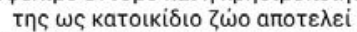

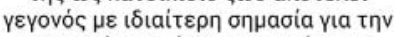



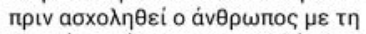

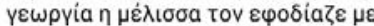

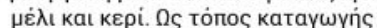



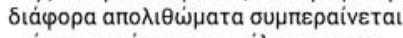

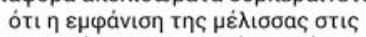

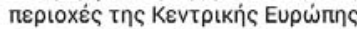

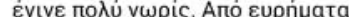

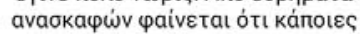

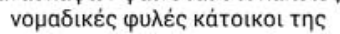
lonaviaç, ot Aıүúntıot kat kátotkoเ

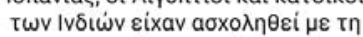
$\mu \varepsilon \lambda$ เбооконіа.
\end{abstract}

Figure 5. Informative content for apiculture

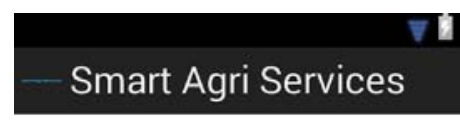

\begin{tabular}{|c|}
\hline 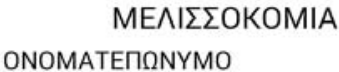 \\
\hline$\triangle I E Y O Y N \Sigma H$ \\
\hline E-MAIL \\
\hline 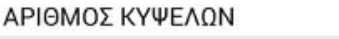 \\
\hline 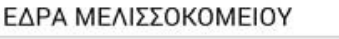 \\
\hline NOMO $\triangle$ IAXEIMA $\Sigma \mathrm{H} \Sigma$ \\
\hline AP. KYKA. AYTOKINHTOY \\
\hline 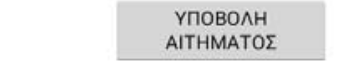 \\
\hline
\end{tabular}

Figure 6. M-government service for apiculture



\begin{tabular}{|c|}
\hline ¿НРОТРОФІА \\
\hline ONOMATEПRNYMO \\
\hline$\triangle I E Y \Theta Y N \Sigma H$ \\
\hline E-MAIL \\
\hline 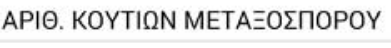 \\
\hline 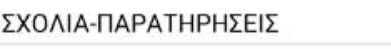 \\
\hline $\begin{array}{l}\text { YПOBONH } \\
\text { AITHMATOE }\end{array}$ \\
\hline
\end{tabular}

Figure 7. M-government service for sericulture

\section{Conclusions}

Digital government can offer to the public administration significant opportunities to achieve better government as the citizens and businesses become more technologically advanced. Indeed, recent advancements on smartphones and the capabilities of the related software, can offer great easiness and wider access and extend the reach of governmental information and services to the public. However, according to the presented overview, the use of smartphones for m-government services is still in its infancy. Few m-government apps exist, especially of the interactive and transformational type, but they are constantly evolving. In this work we propose a transactional m-government app for agriculture as an add-on to an existing e-government portal. The proposed app is easy to use and the user is able to find information and submit requests and applications in a convenient and simple process. They are also able to be up-to-date about the administrative information and processes of their requests. With the use of such apps, farmers could save time and money since they don't need to travel in order to submit applications and documents by physical presence. On the other hand public agencies and local government related to agriculture can lower their administrative burdens and improve their accessibility, effectiveness and efficiency. Farmers and other interested parties in agriculture could gain more by using smartphones as a working tool, and government access medium. The proposed app is in continuous evolving process in order to incorporate more governmental services. It has been tested for screens from 3.5 to 4.7 inches. Also, as future work we plan to make the app available on other platforms such as iOS and WindowsPhone as well as to include functionalities that have to do with payment transactions (e.g. tax payments, subsidies).

\section{References}

Agriculture.com 2011. Smartphones a big trend. http://www.agriculture.com/farm-management/technology/cellphone-and-smart-phones/smartphones-a-big-trend_325-ar20351. (Accessed: 03-03-2014).

Carter, L., Belanger, F. 2005. The utilization of e-government services: citizen trust, innovation and acceptance factors. Information Systems Journal, 15(1).

Chang C., M., Kuo, S., R. 2013. User acceptance of mobile e-government services: An empirical study, Government Information Quarterly, 30(1). 
Chatzinotas, S., Ntaliani, M., Karetsos, S., Costopoulou, C. 2006. Securing M-government Services: the Case of Agroportal. In proceedings: 2nd European mGovernment Conference, pp.61-70. I. Kushchu, C. Broucki, G. Fitzpatrick (eds).

Digby.com, 2013. Mobile Industry Statistics. http://digby.com/mobile-statistics/. (Accessed: 07-03-2014).

Educause.edu, 2013. A Study of Mobile Learning Trends at the U.S. Naval Academy and the Naval Postgraduate School. http://www.educause.edu/ero/article/study-mobile-learning-trends-us-naval-academy-and-navalpostgraduate-school. (Accessed: 09-03-2014).

Eom S. J., Lee, M., Y., Kim, J., H., 2012. The development of public smart phone apps in Korea: empirical approach. Proceedings of the 6th International Conference on Theory and Practice of Electronic Governance ICEGOV'12.

Hung, K. P., Lin C. K., 2013. More communication is not always better? The interplay between effective communication and interpersonal conflict in influencing satisfaction. Industrial Marketing Management 42(8).

ITU-International Telecommunication Union, 2014. Key ICT indicators for developed and developing countries and the world (totals and penetration rates), http:/www.itu.int/en/ITU-D/Statistics/Pages/stat/default.aspx (Accessed: 09-03-2014).

Jain, L., Kumar, H., Singla R. K., 2014. Assessing Mobile Technology Usage for Knowledge Dissemination among Farmers in Punjab. Information Technology for Development.

Lorimer, S. 2012. Mobile Applications- Helping agriculturalists make better decisions. Horticulture Industry Networks. http://hin.com.au/Resources/Mobile-Applications-in-Agriculture.aspx (Accessed: 11-03-2014)

Ntaliani, M., Karetsos, S., Costopoulou, C., 2006. Implementing E-government Services for Agriculture: the Case of Greece. In proceedings: e-Society 2006, P. Isaias, M. McPherson, F. Bannister, pp.243-249.

Ntaliani, M., Costopoulou, C., \& Karetsos, S. 2008. Mobile Government: A Challenge for Agriculture. Government Information Quarterly. 25 (4), 699-716.

Roberts, K., McIntosh, G. 2012. Use of mobile devices in extension and agricultural production - a case study. In proceedings: 16th Australian Agronomy Conference 2012, Armidale, NSW, Australia. http://www.regional.org.au/au/asa/2012/precision-agriculture/8224_robertsk.htm (Accessed: 07-03-2014).

USA Today 2013. Farmers growing comfortable with mobile devices. http://www.usatoday.com/story/news/nation/2013/03/03/farming-technology-ipad-apps/1959139/ (Accessed: 01-03-2014).

Wimmer, M., Grimm, R., Jahn, N., Hampe, J.F., 2013. Mobile participation: exploring mobile tools in eparticipation. ePart 2013, LNCS 8075. 